\title{
Barthel Index of Activities of Daily Living
}

National Cancer Institute

\section{Source}

National Cancer Institute. Barthel Index of Activities of Daily Living. NCI Thesaurus. Code C131914.

A clinical assessment tool designed to measure functional independence and need for assistance in mobility, self-care, and activities of daily living. 